\title{
Effect of probiotic bacteria on prevalence of yeasts in oropharyngeal biofilms on silicone rubber voice prostheses in vitro
}

\author{
H. C. VAN DER MEI, R. H. FREE*, G. J. ELVING, R. VAN WEISSENBRUCH*, F. W. J. ALBERS* \\ and H. J. BUSSCHER
}

Department of Biomedical Engineering, University of Groningen, Antonius Deusinglaan 1, 9713 AV Groningen and *Department of Otorhinolaryngology, University Hospital Groningen, Hanzeplein 1, 9713 EZ Groningen, The Netherlands

\begin{abstract}
The proliferation of yeasts in the mixed bacterial and fungal biofilms colonising silicone rubber voice prostheses in laryngectomised patients is the main cause of malfunctioning of the valve mechanism on the oesophageal side of the prostheses. Indwelling voice prostheses usually have to be replaced every 3-4 months. The consumption of probiotic bacteria is largely motivated by health claims related to the urogenital and lower digestive tract, but not to the upper digestive tract. The present study examined the influence of probiotic bacteria on the prevalence of yeasts in oropharyngeal biofilms on silicone rubber voice prostheses, as formed in a modified Robbins device. Exposure of oropharyngeal biofilms on voice prostheses to suspensions of Bifidobacterium infantis 420 or Enterococcus faecium 603 did not significantly reduce the number of yeasts in the biofilm. However, suspensions of Lactobacillus fermentum B54, L. rhamnosus 744 or $L$. lactis cremoris SK11 led to a reduction in the number of yeasts harvested from the voice prostheses. Suspensions of $L$. casei Shirota and Streptococcus thermophilus B significantly reduced the number of yeasts in the biofilm to $39 \%$ and $33 \%$, respectively. The reduction brought about in yeast prevalence in the mixed biofilm was greatest by exposure to a suspension of $L$. lactis 53 , with yeast prevalence only $4 \%$ of the control. In conclusion, the study demonstrated that the prevalence of yeasts in oropharyngeal biofilms on silicone rubber voice prostheses might be controlled by consumption of probiotic bacteria.
\end{abstract}

\section{Introduction}

Indwelling silicone rubber voice prostheses in laryngectomised patients often fail within 3-4 months after insertion due to the formation of a biofilm on the oesophageal side of the prosthesis causing malfunctioning of the valve mechanism $[1,2]$. Although the biofilm consists of various bacterial strains [3-5], including oral streptococci, skin staphylococci and enterococci, it is the yeasts isolated from malfunctioning prostheses which are generally held responsible for failure of the device, as their adhesion is most tenacious [6]. Scanning electron micrographs have demonstrated yeasts growing into the silicone rubber of explanted prostheses. Candida albicans is most frequently

Received 25 Aug. 1999; revised version received 8 Nov. 1999; accepted 22 Dec. 1999.

Corresponding author: Dr H. C. van der Mei (e-mail: h.c.van.der.mei@med.rug.nl). isolated from voice prostheses, but $C$. tropicalis, $C$. glabrata, C. krusei and C. parapsilosis have also been found. Modifications of the prosthesis surface, adjustment of dietary components or restoration of adequate salivary levels in the oral cavity are being explored to prolong the life-time of indwelling voice prostheses [7]. An alternative approach, hitherto rarely investigated, would be to challenge the colonising yeasts with competing probiotic bacteria.

Yeasts are seldom found in a biofilm without adhering bacteria and it has been suggested that their presence is essential in maintaining the integrity of mixed biofilms on surfaces [8]. Verran and Motteram [9] demonstrated that the presence of Streptococcus sanguis was a prerequisite for the adherence of $C$. albicans to denture acrylic. Yet, there are also certain bacterial strains that are known to compete effectively with yeasts in their colonisation of surfaces. Lactobacilli have a definitive role in the prevention of vaginosis [10], lactococci 
produce antimycotics [11] and thermophilic streptococci release biosurfactants that interfere with the adhesion of yeasts to silicone rubber [12].

The growth of biofilms on silicone rubber voice prostheses under laboratory conditions, showing similar features to those observed in vivo, including ingrowth into the silicone rubber, has only recently become possible [13]. A teleological approach [14] may be used in which a partly identified mixture of yeasts and bacteria, representing the total cultivable microflora from an explanted prosthesis, is employed as an inoculum. Voice prostheses have been inserted in a modified Robbins device and inoculated with the total cultivable microflora from an explanted prosthesis, complemented with yeasts. Cycling the device through periods of feast and famine permits growth of tenaciously adhering mixed biofilms on the prostheses with ingrowth features that cannot be distinguished from in-vivo biodeterioration seen on explanted prostheses. Interestingly, in a reductionistic approach with isolated single strains, biofilms resembling those found in vivo could not be grown in the modified Robbins device. For an investigation of isolated single factors influencing biofilm formation on voice prostheses, like the influence of probiotic bacteria, a laboratory model is indispensable, as it is not possible to control dietary factors, outside temperature and humidity over any prolonged period of time in vivo.
There is an increasing interest world-wide in alternative approaches [15] to control biofilms in the human body that are not based on antibiotics or antimycotics [1618]. The aim of this study was to investigate whether the prevalence of yeasts in mixed oropharyngeal biofilms on silicone rubber voice prostheses could be reduced in vitro by exposing the prosthesis biofilm to suspensions of various probiotic bacteria.

\section{Materials and methods}

\section{Voice prostheses and biofilm formation}

'Low resistance' silicone rubber Groningen voice prostheses were provided by Medin Instruments and Supplies (Groningen, The Netherlands) and placed in three transparent modified Robbins devices, as shown schematically in Fig. 1. Each Robbins device was equipped with four Groningen voice prostheses. The total cultivable microflora from an explanted Groningen voice prosthesis, containing a variety of strains of yeast and bacteria, including $C$. albicans, C. tropicalis, streptococci and staphylococci, were cultured in a mixture containing Brain Heart Infusion Broth (Oxoid) $30 \%$ and defined yeast medium (/L: glucose $7.5 \mathrm{~g}$, $\left(\mathrm{NH}_{4}\right)_{2} \mathrm{SO}_{4} \quad 3.5 \mathrm{~g}, \quad$ L-asparagine $1.5 \mathrm{~g}, \quad$ L-histidine $10 \mathrm{mg}$, DL-methionine $20 \mathrm{mg}$, DL-tryptophane $20 \mathrm{mg}$, $\mathrm{KH}_{2} \mathrm{PO}_{4} 1 \mathrm{~g}, \mathrm{MgSO}_{4} .7 \mathrm{H}_{2} \mathrm{O} 500 \mathrm{mg}, \mathrm{NaCl} 500 \mathrm{mg}$, $\mathrm{CaCl}_{2} .2 \mathrm{H}_{2} \mathrm{O} 500 \mathrm{mg}$, yeast extract $100 \mathrm{mg}, \mathrm{H}_{3} \mathrm{BO}_{3}$

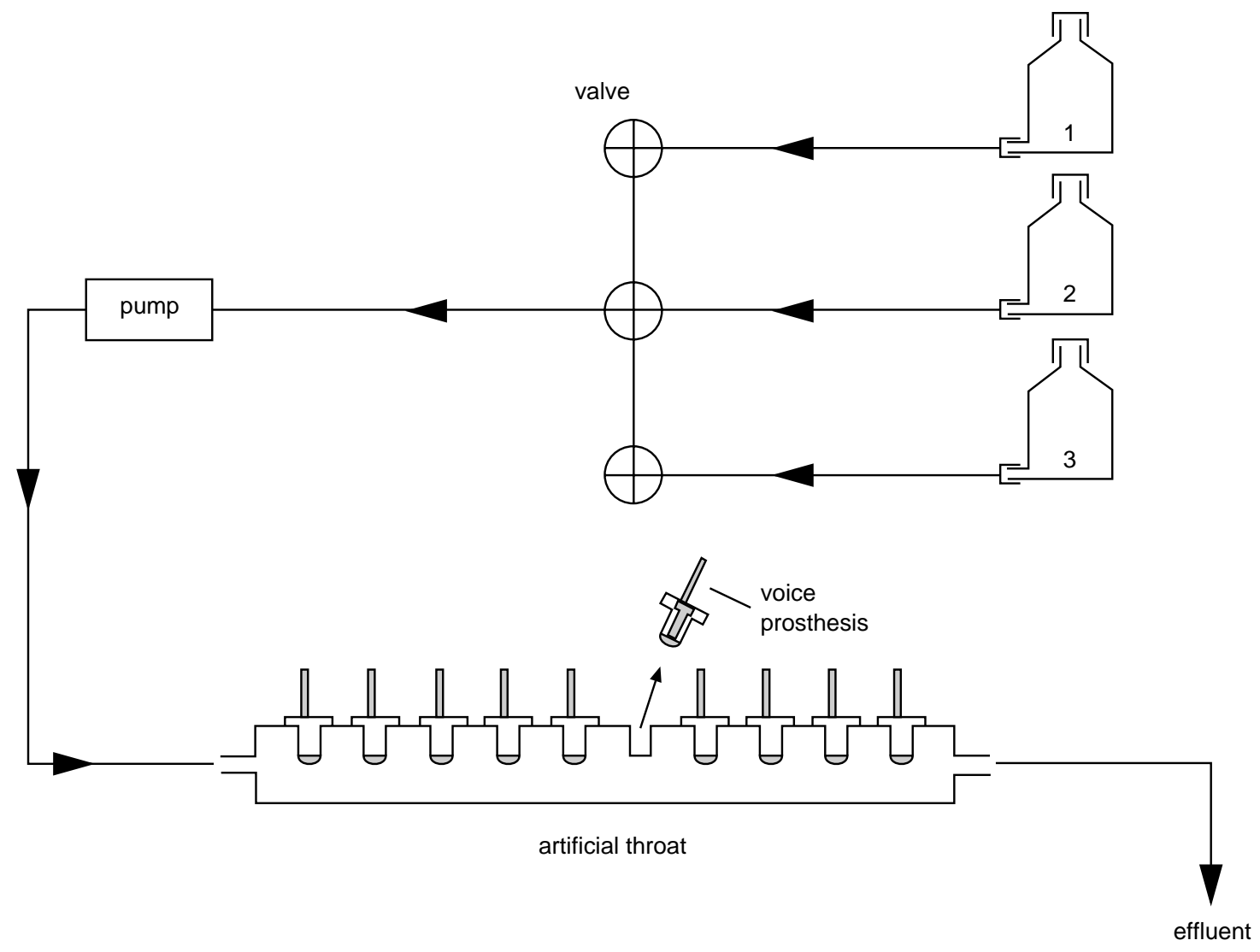

Fig. 1. Schematic presentation of the artificial throat, equipped with Groningen button voice prostheses. 
$500 \mu \mathrm{g}, \quad \mathrm{ZnSO}_{4} .7 \mathrm{H}_{2} \mathrm{O} \quad 400 \mu \mathrm{g}, \quad \mathrm{Fe}(\mathrm{III}) \mathrm{Cl}_{3} \quad 120 \mu \mathrm{g}$, $\mathrm{Na}_{2} \mathrm{MoO}_{4} \cdot 2 \mathrm{H}_{2} \mathrm{O} 200 \mu \mathrm{g}, \quad \mathrm{KI} 100 \mu \mathrm{g}, \mathrm{CuSO}_{4} .5 \mathrm{H}_{2} \mathrm{O}$ $40 \mu \mathrm{g}) 70 \%$. This mixed culture was used to inoculate the voice prostheses in the Robbins devices. Subsequently, a biofilm was allowed to grow on the voice prostheses over 3 days, in ambient air and at room temperature. On the fourth day, the throats were flushed with phosphate-buffered saline (PBS; $10 \mathrm{mM}$ potassium phosphate, $150 \mathrm{mM} \mathrm{NaCl}, \mathrm{pH}$ 7.0) to remove remnants of the growth medium.

One modified Robbins device served as a control and was perfused with $650 \mathrm{ml}$ of PBS $(35 \mathrm{ml} / \mathrm{min})$ before being left in a moist environment. In the other Robbins devices, $650 \mathrm{ml}$ of a bacterial suspension were perfused, after which the device was also left drained. To remove remnants of the bacterial suspension before the next perfusion, PBS was perfused through the device, followed by the bacterial suspension again. This perfusion scheme was repeated three times a day. At the end of the day, the modified Robbins devices were filled with growth medium for $30 \mathrm{~min}$, while overnight the devices were left in the moist environment of the drained throat. Experiments were continued for 12 days at room temperature and the tracheal sides of the prostheses were left in ambient air, similar to the situation with a stoma.

\section{Bacterial strains and growth conditions}

The bacterial strains used in this study are listed in Table 1, together with their growth medium and source. Test strains were inoculated from agar plates into the specified growth medium and incubated for $24 \mathrm{~h}$ at $37^{\circ} \mathrm{C}$. The resultant culture was used to inoculate a second fresh medium that was similarly incubated for $16 \mathrm{~h}$. All cultures were incubated aerobically at $37^{\circ} \mathrm{C}$ except for the strains of Lactobacillus spp. which were cultured in $\mathrm{CO}_{2} \quad 5 \%$ in air. Each bacterial suspension was centrifuged at $5000 \mathrm{~g}$ for $5 \mathrm{~min}$ and the pellet was washed twice with demineralised water. After counting in a Bürker-Türk counting chamber, bacterial pellets were resuspended in demineralised water at a concentration of $1 \times 10^{9}$ bacteria $/ \mathrm{ml}$. The $\mathrm{pH}$ of these suspensions is listed in Table 1.

\section{Evaluation of biofilms}

After removal of the voice prostheses from the modified Robbins devices, biofilm formation on the valve side of the prosthesis was assessed qualitatively by electron microscopy and quantitatively on the other three sides by plating of the biofilms on to agar plates.

For scanning electron microscopy (SEM), voice prostheses were flushed with sucrose $6.8 \%$ in $0.1 \mathrm{M}$ cacodylate buffer ( $\mathrm{pH}$ 7.4), fixed and stained in gluteraldehyde $2 \%$ and ruthenium red $0.2 \%$ in $0.1 \mathrm{M}$ cacodylate buffer at $4{ }^{\circ} \mathrm{C}$ and flushed again. Postfixation and staining were performed in $\mathrm{OsO}_{4} 1 \%$ and ruthenium red $0.2 \%$ in cacodylate buffer by gently shaking for $3 \mathrm{~h}$ at room temperature. Buffer washes and dehydration involved the following rinsing procedures: $20 \mathrm{~min}$ in sucrose $6.8 \%$ in $0.1 \mathrm{M}$ cacodylate buffer; $3 \times 10 \mathrm{~min}$ in bi-distilled water; $20 \mathrm{~min}$ in ethanol at respective concentrations of 30,50 and $70 \%$ and finally $4 \times 30 \mathrm{~min}$ in ethanol $100 \%$. After critical-point drying with $\mathrm{CO}_{2}$ for $4 \mathrm{~h}$, the voice prostheses were sputtercoated with gold/palladium particles $(15 \mathrm{~nm})$. SEM observations were made with a JEOL 6301 electron microscope, with different magnifications at $15-25 \mathrm{kV}$.

The number of colonising yeasts (cfu) was determined after serial dilution in reduced transport fluid before inoculation on to plates of brain-heart infusion agar. The biofilms were removed by scraping the total biofilm from the voice prosthesis, which was suspended in reduced transport fluid and sonicated for $60 \mathrm{~s}$. Agar plates were incubated at $37^{\circ} \mathrm{C}$ in aerobic conditions for 3 days. The number of fungal $\mathrm{cfu} / \mathrm{cm}^{2}$ was determined for all prostheses exposed to each probiotic strain. The discrimination between the resulting colony types for the yeasts and bacteria was done visually in combination with phase contrast microscopy. Enumeration of the total number of bacteria present in the biofilm was only done for the control, by plating on blood agar.

\section{Results}

Voice prostheses in the control Robbins device were consistently covered with a thick biofilm. Yeasts were recovered from the prostheses at a mean level of

Table 1. Probiotic strains and growth conditions used in this study

\begin{tabular}{lll}
\hline Strain & Growth medium & Source \\
\hline Streptococcus thermophilus B & M17 supplemented with 1\% sucrose & NIZO, The Netherlands \\
Lactococcus lactis 53 & BHI & Nutricia, The Netherlands \\
Lactococcus lactis cremoris SK11 & BHI supplemented with 0.5\% lactose & NIZO, The Netherlands \\
Lactobacillus rhamnosus 744 (ATCC7469) & MRS & Nutricia, The Netherlands \\
Lactobacillus fermentum B54 & MRS & Dr G. Reid, Canada \\
Lactobacillus casei Shirota & MRS & Isolated from Yakult fermented-milk drink \\
Enterococcus faecium 603 & BHI & 4.3 \\
Bifidobacterium infantis 420 & Defined yeast medium & Numico, The Netherlands \\
\hline
\end{tabular}


$3 \times 10^{7} \mathrm{cfu} / \mathrm{cm}^{2}$. Results were obtained from four experiments involving a total of 12 prostheses. The mean bacterial flora recovered from the prostheses was $1 \times 10^{8} \mathrm{cfu} / \mathrm{cm}^{2}$.

The numbers of yeasts harvested from the prostheses after exposure of the oropharyngeal biofilms to various suspensions of probiotic bacteria are shown in Fig. 2. The number of yeasts isolated from prostheses in the control device was set to $100 \%$. Exposure of the biofilms to suspensions of $B$. infantis 420 and $E$. faecium 603 did not significantly reduce $(\mathrm{p}>0.5)$ the number of yeasts in the biofilm. Suspensions of $L$. fermentum B54, L. rhamnosus 744 and L. lactis cremoris SK11 produced a reduction $(\mathrm{p}<0.2)$ in the number of yeasts harvested from the voice prostheses. Suspensions of L. casei Shirota and S. thermophilus B $(\mathrm{p}<0.1)$ reduced the number of yeasts in the biofilm to $39 \%$ and $33 \%$, respectively. The greatest reduction in yeast prevalence in the mixed biofilm $(4 \%$ of the control) was produced by a suspension of L. lactis 53 $(\mathrm{p}<0.01)$.

Scanning electron micrographs of the control biofilm and of biofilms after exposure to $S$. thermophilus B, $L$. lactis 53 and L. rhamnosus 744 suspensions are shown in Fig. 3. Ingrowth features of colonising yeasts together with bacteria can be clearly discerned for prostheses removed from the control device. Despite reduced yeast counts, fungal colonies on prostheses exposed to a suspension of $S$. thermophilus B also showed similar ingrowth to the control, with a relatively greater involvement of bacteria when compared with the control. The L. lactis 53 and $L$. rhamnosus 744 suspensions fully inhibited the ingrowth of yeasts and bacteria, as shown in Fig. 3 .

\section{Discussion}

The present study examined the effect of exposing a mixed oropharyngeal biofilm on silicone rubber voice prostheses to suspensions of probiotic bacteria. A reduction in the number of yeasts found in the biofilms may be beneficial, as proliferation of yeasts on the prosthesis surface is generally considered to be the main cause of device failure. Amongst the strains of lactobacilli studied, L. casei Shirota from a fermented milk product, L. lactis 53 and S. thermophilus B, isolated from heat exchanger plates in a pasteurising machine, caused the greatest reduction in the prevalence of yeast in the biofilms. These reductions appeared to be unrelated to the $\mathrm{pH}$ of the bacterial suspensions used. Previously, it has been demonstrated that mice with a normal, healthy oral microflora were highly resistant to colonisation by candida, whilst germ-free mice were extremely susceptible to candidal infection [19]. This susceptibility to candidal infection could be almost completely prevented by the restoration of a healthy microflora consisting of probiotic

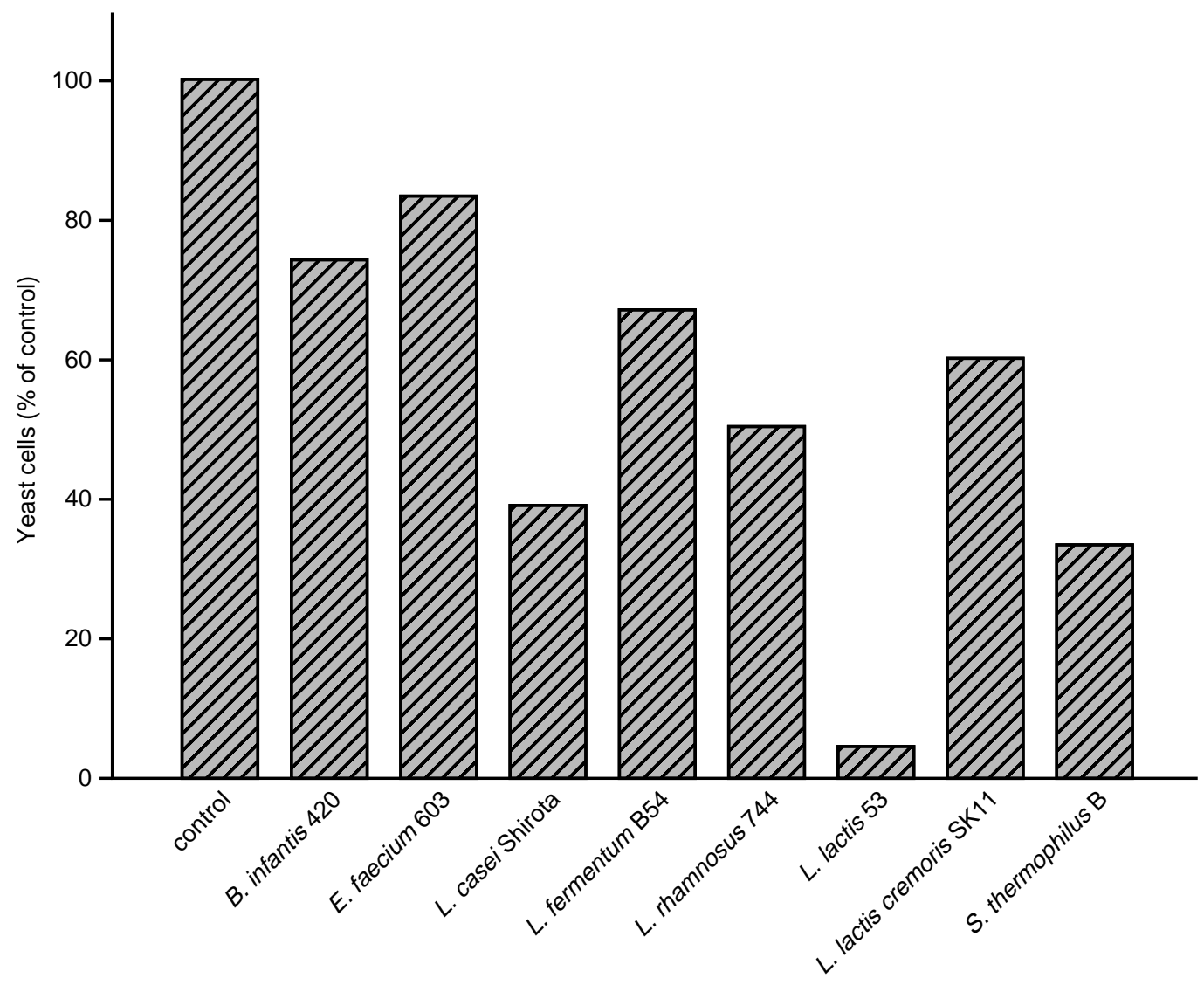

Fig. 2. Recovery of yeasts from voice prostheses in the artificial throat after perfusion with different probiotic bacteria. All data are expressed as percentages of the control (100\%), with a $30 \%$ mean difference over duplicate runs. 

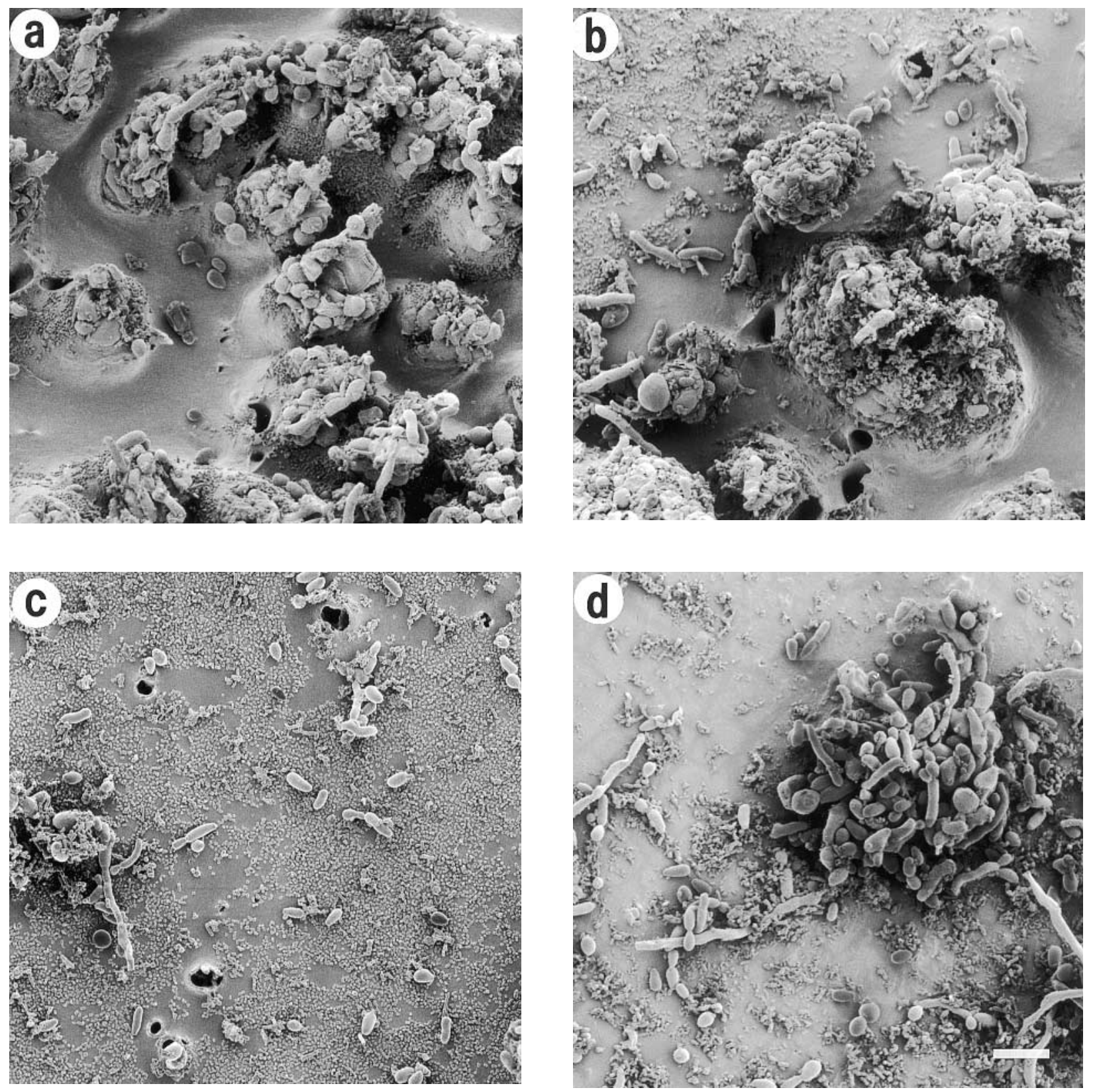

Fig. 3. Scanning electron micrographs of Groningen button voice prostheses removed from the artificial throats after perfusion three times daily with different probiotic bacteria or potassium phosphate buffer. Bar $=10 \mu \mathrm{m}$. (a) Control, showing heavy biofilm formation; (b) after exposure to S. thermophilus B suspension; (c) after exposure to L. lactis 53 suspension; (d) after exposure to L. rhamnosus 744 suspension.

bacteria [20]. Disruption of the healthy oral microflora often occurs in laryngectomised patients due to reduced salivary flow following radiotherapy [21]. A similar situation occurs in patients with Sjögren's syndrome [22]. Furthermore, the wearing of dentures can lead to a candida-associated denture stomatitis, a condition caused by a disruption of the oral microflora due to the presence of a biomaterials prosthesis [23].

Although antimycotics have been used to reduce biofilm formation on voice prostheses, the success of this treatment is variable. Complete prevention of a biofilm is likely to be impossible and the ingrowth of the yeasts into the silicone rubber offers a protective environment against any antimicrobial therapy. A slow- release tablet containing the antimycotic miconazole nitrate has been reported to eliminate candida from within the oropharynx of laryngectomised patients, but significant numbers of yeasts persisted in the biofilms on the valve side of the prostheses [2]. Similar results were found with the use of amphotericin B lozenges $[3,24]$ and rinsing the oral cavity twice a day with nystatin suspension $[25,26]$. However, the long-term use of antimycotics is associated with an increased likelihood of inducing antimycotic resistance [15].

The use of probiotic bacteria to reduce yeast prevalence in biofilms on voice prostheses remains a worthwhile approach. Health claims associated with the use of probiotic bacteria are usually confined to the lower 
digestive and urogenital tract [10,27,28]. For example, L. acidophilus has appeared to be effective in preventing candidal vaginitis in patients [29]. Lactobacilli are part of the healthy vaginal microflora [10] and can interfere with uropathogen colonisation of the urogenital tract by production of hydrogen peroxide and lactic acid, competitive adhesion and displacement and the release of anti-adhesive biosurfactants $[10,30,31]$. The release of anti-adhesive biosurfactants can be an especially powerful defence weapon against other colonising organisms, as the biosurfactant release of one adhering organism suffices to cover a substratum area 1000 times the geometrical area of the lactobacillus. S. thermophilus also releases anti-adhesive biosurfactants [32], that have been demonstrated to interfere with the initial adhesion of $C$. albicans and $C$. tropicalis to silicone rubber [12]. L. lactis 53 is not a biosurfactant producer but is known to release antimycotics [11].

In conclusion, the results of the present study indicate the potential health benefits of probiotic bacteria in the prevention of fungal infections occurring in the upper digestive tract. Specifically, such an approach could be helpful for patients who have undergone total laryngectomy with subsequent provision of an indwelling voice prosthesis.

\section{References}

1. Van Den Hoogen FJA, Oudes MJ, Hombergen G, Nijdam HF, Manni JJ. The Groningen, Nijdam and Provox voice prostheses: a prospective clinical comparison based on 845 replacements. Acta Otolaryngol 1996; 116: 119-124.

2. Van Weissenbruch R, Bouckaert S, Remon JP, Nelis HJ, Aerts R, Albers FWJ. Chemoprophylaxis of fungal deterioration of the Provox silicone tracheoesophageal prosthesis in postlaryngectomy patients. Ann Otol Rhinol Laryngol 1997; 106: 329-337.

3. Mahieu HF, Van Saene HKF, Rosingh HJ, Schutte HK. Candida vegetations on silicone voice prostheses. Arch Otolaryngol Head Neck Surg 1986; 112: 321-325.

4. Izdebski K, Ross JC, Lee S. Fungal colonization of tracheoesophageal voice prosthesis. Laryngoscope 1987; 97: 594-597.

5. Neu TR, Verkerke GJ, Herrmann IF, Schutte HK, Van der Mei HC, Busscher HJ. Microflora on explanted silicone rubber voice prostheses: taxonomy, hydrophobicity and electrophoretic mobility. J Appl Bacteriol 1994; 76: 521-528.

6. Neu TR, Van der Mei HC, Busscher HJ, Dijk F, Verkerke GJ. Biodeterioration of medical-grade silicone rubber used for voice prostheses: a SEM study. Biomaterials 1993; 14: 459-464.

7. Busscher HJ, Van der Mei HC. Biofilm formation and its prevention on silicone rubber voice prostheses. In: Blom ED, Singer MI, Hamaker R (eds) Tracheoesophageal voice restoration following total laryngectomy. San Diego, Singular Publishing Group. 1998: 89-102.

8. Millsap KW, Van der Mei HC, Bos R, Busscher HJ. Adhesive interactions between medically important yeasts and bacteria. FEMS Microbiol Rev 1998; 21: 321-336.

9. Verran J, Motteram KL. The effect of adherent oral streptococci on the subsequent adherence of Candida albicans to acrylic in vitro. J Dent 1987; 15: 73-76.

10. Reid G, Bruce AW, McGroarty JA, Cheng KJ, Costerton JW. Is there a role for lactobacilli in prevention of urogenital and intestinal infections? Clin Microbiol Rev 1990; 3: 335-344.
11. Batish VK, Lal R, Chander H. Effects of nutritional factors on the production of antifungal substance by Lactococcus lactis spp. lactis biovar diacetylactis. Aust J Dairy Technol 1990; 45: 74-76.

12. Busscher HJ, Van Hoogmoed CG, Geertsema-Doornbusch GI, Van der Kuijl-Booij M, Van der Mei HC. Streptococcus thermophilus and its biosurfactants inhibit adhesion by Candida spp. on silicone rubber. Appl Environ Microbiol 1997; 63: 3810-3817.

13. Leunisse C, Van Weissenbruch R, Busscher HJ, Van der Mei HC, Albers FWJ. The artificial throat: a new method for standardization of in vitro experiments with tracheoesophageal voice prostheses. Acta Otolaryngol 1999; 119: 604-608.

14. Rolla G, Waaler SM, Kjaerheim V. Concepts in dental plaque formation. In: Evans L, Busscher HJ (eds) Oral biofilms and plaque control. Amsterdam, Harwood Academic Publishers. 1998: $1-18$.

15. Denning DW. Can we prevent azole resistance in fungi? Lancet 1995; 346: 454-455.

16. Fuller R. Probiotics: their development and use. In: Fuller R, Heidt PJ, Rusch V, Van der Waaij D (eds) Probiotics: prospects of use in opportunistic infections. Herborn-Dill, Germany, Institute for Microbiology and Biochemistry. 1995: 1-8.

17. Havenaar R, Huis in’t Veld JHJ. Probiotics: a general view. In: Wood BJB (ed) The lactic acid bacteria, vol 1. The lactic acid bacteria in health and disease. London, Elsevier. 1992: $151-170$.

18. Sanders ME. Lactic acid bacteria and human health. In: Fuller R, Heidt PJ, Rusch V, Van der Waaij D (eds) Probiotics: prospects of use in opportunistic infections. Herborn-Dill, Germany, Institute for Microbiology and Biochemistry. 1995: $126-140$.

19. Van Wyk CW, Basson NJ, Theunissen F. Induced candidosis in mice with artificially established oral flora. J Dent Assoc $S$ Afr 1996; 51: 427-432.

20. Wagner RD, Pierson C, Warner T et al. Biotherapeutic effects of probiotic bacteria on candidiasis in immunodeficient mice. Infect Immun 1997; 65: 4165-4172.

21. Brown LR, Dreizen S, Handler S, Johnston DA. Effect of radiation-induced xerostomia on human oral microflora. $J$ Dent Res 1975; 54: 740-750.

22. MacFarlane TW. The oral ecology of patients with severe Sjögren's syndrome. Microbios 1984; 41: 99-106.

23. Webb BC, Thomas CJ, Willcox MD, Harty DW, Knox KW. Candida-associated denture stomatitis. Aetiology and management: a review. Part 1. Factors influencing distribution of Candida species in the oral cavity. Aust Dent $J$ 1998; 43: $45-50$.

24. Van Lith-Bijl JT, Mahieu HF, Patel P, Zijlstra RJ. Clinical experience with the low-resistance Groningen button. Eur Arch Otorhinolaryngol 1992; 249: 354-357.

25. Blom ED, Hamaker RC. Tracheoesophageal voice restoration following total laryngectomy. In: Myers EN, Suen JY (eds) Cancer of the head and neck, 3rd edn. Philadelphia, WB Saunders. 1996: 839-852.

26. Blom ED, Singer MI. Disinfection of silicone voice prostheses. Arch Otolaryngol Head Neck Surg 1986; 112: 1303.

27. Blomberg L, Henriksson A, Conway PL. Inhibition of adhesion of Escherichia coli $\mathrm{K} 88$ to piglet ileal mucus by Lactobacillus spp. Appl Environ Microbiol 1993; 59: 34-39.

28. Holzapfel WH, Haberer P, Snel J, Schillinger U, Huis in 't Veld JHJ. Overview of gut flora and probiotics. Int $J$ Food Microbiol 1998; 41: 85-101.

29. Elmer GW, Surawicz CM, McFarland LV. Biotherapeutic agents: a neglected modality for the treatment and prevention of selected intestinal and vaginal infections. JAMA 1996; 275: 870-876.

30. Hawthorn LA, Reid G. Exclusion of uropathogen adhesion to polymer surfaces by Lactobacillus acidophilus. J Biomed Mater Res 1990; 24: 39-46.

31. Velraeds MCM, Van der Mei HC, Reid G, Busscher HJ. Physicochemical and biochemical characterization of biosurfactants released by Lactobacillus strains. Coll Surf B: Biointerfaces 1996; 8: 51-61.

32. Busscher HJ, Neu TR, Van der Mei HC. Biosurfactant production by thermophilic dairy streptococci. Appl Microbiol Biotechnol 1994; 41: 4-7. 